\title{
The influence of a systematic risk assessment and a training course in aggression management on seclusion rates in Switzerland: a multi center study
}

\author{
Ian Needham*1 and Christoph Abderhalden ${ }^{2}$
} \author{
and Social Education Research Unit, Bolligenstrasse 111, 3000 Bern, Switzerland \\ * Corresponding author \\ from WPA Thematic Conference. Coercive Treatment in Psychiatry: A Comprehensive Review \\ Dresden, Germany. 6-8 June 2007 \\ Published: 19 December 2007 \\ BMC Psychiatry 2007, 7(SuppI I):SI37 doi:10.1 I86/I47I-244X-7-SI-SI37
}

Address: ${ }^{1}$ University of Applied Sciences St. Gallen, Tellstrasse 2, 9001 St. Gallen, Switzerland and ${ }^{2}$ University Bern Psychiatric Services, Nursing

This abstract is available from: http://www.biomedcentral.com/I47I-244X/7/SI/SI 37

(c) 2007 Needham and Abderhalden; licensee BioMed Central Ltd.

\section{Background}

To explore the influence of a systematic risk assessment and a training course in aggression management on seclusion rates in Switzerland.

\section{Methods}

We conducted a multi-center partially randomized controlled trial on 24 acute psychiatric admission wards in the German speaking region of Switzerland. The wards were cluster randomized into 5 study arms (training course, systematic risk assessment, systematic risk assessment and training course combined, control group, preference wards utilizing only the systematic risk assessment). Aggressive incidents and coercive measures (seclusion, involuntary medication, and fixation) were recorded at pre and post intervention.

\section{Results}

We recorded 1,256 coercive measures in 81,255 treatment days of the trial. 1,134 coercive measures were administered in conjunction with aggressive behavior. In the preference arm the coercion rates fell from 1.432 (95\% CI $1.160-1.749)$ to $0.552(95 \%$ CI $0.402-0.788)$ per 100 treatment days. A significant drop in coercion rates per 1000 treatment days were recorded on the wards having introduced the training course (pre test 23.81, 95\% CI = 20.98 - 26.93 versus $17.699,95 \% \mathrm{CI}=14.908-20.865$ post test) and on the risk assessment preference wards test $(15.811,95 \% \mathrm{CI}=12.945-19.128$ versus $6.265,95 \% \mathrm{CI}$
$=4.515-8.468)$. The main reasons for seclusion were the reduction of stimuli (498), treatment refusal (474), danger to others (460), and aggressive behavior (306).

\section{Conclusion}

A systematic risk assessment (preference arm) and a training course in aggression management are effective in reducing seclusion in psychiatric acute admission wards. The other two interventions (a systematic risk assessment alone and in combination with a training course) have no influence on seclusion rates. The preference arm wards faired well on the reduction of all coercive measures and seclusion. This finding may point to the possible role of motivation as a key factor in the reduction of coercion. 